\title{
Jerusalem Artichoke Powder Mixed in Enteral Feeding for Patients Who have Diarrhea in Surgical Intensive Care Unit: A Method of Preparation and a Pilot Study
}

\author{
Kaweesak Chittawatanarat ${ }^{1}$, Suthat Surawang ${ }^{2}$, Piyawan Simapaisan ${ }^{3}$, Kunchit Judprasong ${ }^{4}$
}

\begin{abstract}
Aim and objective: The Jerusalem artichoke (Helianthus tuberosus L.) is a tuber with high soluble fiber. The objective of this study was to demonstrate the method of preparation and pilot test this substance as an additive to enteral feeding.

Materials and methods: We processed Jerusalem artichoke into a 600 micrometers powder, tested its properties, and pilot tested its use in patients who had diarrhea (King's stool score $\geq 12$ ) in a surgical intensive care unit. Two grams of Jerusalem artichoke powder were mixed in each $100 \mathrm{~mL}$ of hospital enteral feeding formula and administered for 5 days.

Results: Artichoke powder slightly increased the viscosity of enteral feeding formula. The dietary fiber content of the mixture was 20.8-21.6 $\mathrm{g} \%$ and the content of fructans was $66.0-71.5 \mathrm{~g} \%$. In the pilot study in 11 patients, diarrhea was improved (diarrhea score $<12)$ in $7 / 11(63.6 \%)$ patients by day 5 . Improvement in diarrhea started on day 2 [median different diarrhea score (interquartile range): $-4(-8$ to 0$) ; p=0.03$ ] and peaked by days 4 and $5[-7(-10$ to -3$) ; p<0.01$ and $-8(-12$ to -4$) ; p<0.01$, respectively]. There were no complications during the study except three patients had a high gastric residual volume $(>200 \mathrm{~mL})$.

Conclusion: Processed powder of Jerusalem artichoke tuber has a high fiber content and increases viscosity of enteral feeding solutions only slightly. When administered as part of enteral nutrition to critically ill surgical patients, the diarrhea score improves in most patients.

Keywords: Diarrhea, Fructans, Jerusalem artichoke, Soluble fiber, Surgical critically ill.

Indian Journal of Critical Care Medicine (2020): 10.5005/jp-journals-10071-23575
\end{abstract}

\section{INTRODUCTION}

Jerusalem artichoke (Heliantus tubersus L.), called Kaen-ta-wan in Thai, is a tuber crop widely cultivated in the northern and northeastern regions of Thailand. ${ }^{1}$ It is comprised of a high proportion of soluble fiber including inulin and oligofructose. ${ }^{2}$ Our previous report in surgical critically ill septic patients demonstrated that a fiber-enriched diet decreases the diarrhea score. ${ }^{3}$ Although the difference in the incidence of diarrhea was lower in the study group (mixed fiber $23.5 \%$ and control $47.1 \%$ ), this study did not show a statistically significant effect due to the small number of enrolled subjects. ${ }^{3}$ In Thailand, there are differences in hospital preparations of enteral feeding formulas. In our nutrition department service, the standard hospitalized formula is a mixture of pumpkin, chicken meat, egg, and soy oil. These macronutrient ingredients contain $12 \%$ protein, $50-55 \%$ carbohydrate, $33-38 \%$ fat, and a very low amount of fiber. The mixing of artichoke into an enteral feeding formula could increase the amount of soluble fiber. However, artichoke is a seasonal crop. The processing of artichokes into dry power could create a continuous supply. The objective of this study was to describe the process of producing artichoke powder, measure the physical properties and amount of fiber in an artichoke-enriched enteral feeding formula, and to measure the effect of this mixture on diarrhea in patients who are admitted to a surgical intensive care unit (SICU).

\section{Materials and Methods}

\section{Processing of Artichoke into Powder}

The artichokes were harvested from an artichoke farm in Chiang Mai, Thailand. The artichoke processing is summarized in Flowchart 1.
${ }^{1}$ Department of Surgery, Faculty of Medicine, Chiang Mai University, Chiang Mai, Thailand

2,3 Department of Product Development Technology, Faculty of AgroIndustry, Chiang Mai University, Chiang Mai, Thailand

${ }^{4}$ Institute of Nutrition, Mahidol University at Salaya, Nakhon Pathom, Thailand

Corresponding Author: Kaweesak Chittawatanarat, Department of Surgery, Faculty of Medicine, Chiang Mai University, Chiang Mai, Thailand, Phone: +6653935533, e-mail: kchittaw@gmail.com

How to cite this article: Chittawatanarat K, Surawang S, Simapaisan $P$, Judprasong K. Jerusalem Artichoke Powder Mixed in Enteral Feeding for Patients Who have Diarrhea in Surgical Intensive Care Unit: A Method of Preparation and a Pilot Study. Indian J Crit Care Med 2020;24(11):1051-1056.

Source of support: This study was funded by Faculty of Medicine, Chiang Mai University (funding number SUR-2557-02376), and Cerebos awards.

Conflict of interest: None

After cleaning the artichokes with tap water, they were blanched with $5 \%$ sodium hydroxide at $90^{\circ} \mathrm{C}$ for 90 seconds, rinsed five times in cool water, and then cooled at room temperature and peeled. The peeled artichokes were immersed into $3 \%$ citric acid for 15 minutes, then cut into $1.5 \mathrm{~cm}$ pieces. The cut artichokes were left at room air to drain for 10 minutes. Then they were dried in a rotary vacuum microwave oven for 90 minutes (vacuum microwave dryer, March Cool Co., Ltd Thailand) until the moisture content was less than $15 \%$. The products were dried again in a hot dry air oven (Hot air dyer, 
Flowchart 1: Processes for Jerusalem artichoke powder production

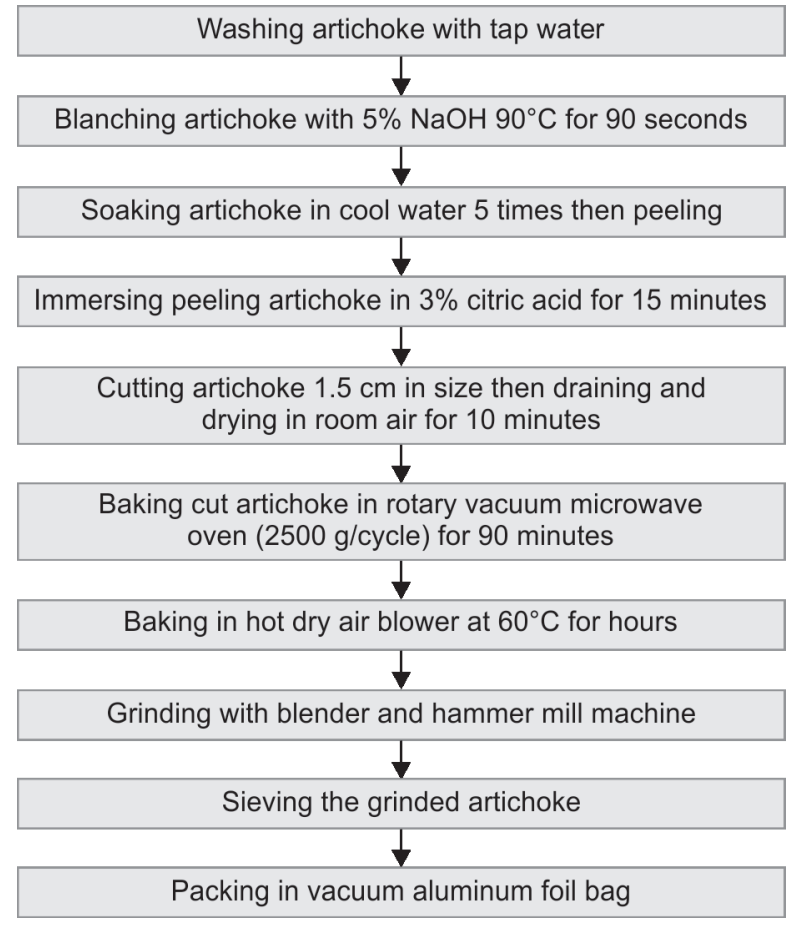

Memmert, Germany) at $60^{\circ} \mathrm{C}$ for 4 hours. The dried products were ground with a blender and hammer mill machine, and then sieved to retain particles that were 600 micrometers in size (Sieve shaker, Restex, UK). Finally, the dried powder of artichoke was packed in a vacuum aluminum foil bag and refrigerated at $2-4^{\circ} \mathrm{C}$.

\section{Physical and Chemical Measurements}

The physical characteristics of artichoke powder were investigated by collaborators at the Faculty of Agro-Industry, Chiang Mai University, Chiang Mai, Thailand. The total amount of raw material per total yield product by weight was recorded [\% yield = (weight of dry powder/weight of raw material) $\times 100$ ]. The moisture content was reported in percent by weight. The water activity $\left(a_{\mathrm{w}}\right)$ was measured by Aqua LAB (Model Series 3, Decagon Device Inc., USA) ( $a_{w}=$ equilibrium relative humidity $\left.(\mathrm{ERH}) / 100\right)$. The color of the artichoke powder was reported according to the Commission Internationale de I'Eclairage (CIE) system, which included $L^{*}$ (lightness), $a^{*}$ (redness), and b*(yellowness), which were measured by a colorimeter (Konica-Minolta, Model CR-410, Japan). The viscosity and solubility were measured by a rapid viscosity analyzer (RVA) and a texture analyzer (TA) [Brookfield (model DV-II+ viscometer)] and was reported in rapid visco unit (RVU). The composition of dietary fiber and fructans (inulin and oligofructose) was measured according to the method of the association of official analytical chemists (AOAC, 2016, method No. 985.29 and 997.08, respectively) (at Institute of nutrition, Mahidol University, Nakorn Pathom, Thailand). ${ }^{4,5}$

\section{Pilot Enrollment and Intervention}

This study was a single arm design, before and after intervention study. The objective of this pilot study was to measure the clinical effects of processing Jerusalem artichoke in powder form to mix in an enteral feeding formula for patients who had diarrhea in a SICU. This study was approved by the Ethics Committee, Faculty of
Medicine, Chiang Mai University (Study code number: SUR-255702376). All participants provided a written informed consent prior to participation. All the enrolled patients were more than 18 years of age, had stable hemodynamic measurements, were receiving an enteral diet via nasogastric tube, were tolerating at least $60 \%$ of that diet without interruption, and who had a diarrhea score greater than 12 by the King's stool chart. We excluded patients who were receiving medications that might cause diarrhea such as metoclopramide, quinidine, xylitol, magnesium, erythromycin, and aminophylline; we also excluded patients who needed an enema for any cause. Patients who were had infectious diarrhea or who had undergone a total colectomy or ileostomy were excluded.

After patient consent, the processed artichoke was mixed into the enteral formula in the amount of $2 \mathrm{~g} / 100 \mathrm{~mL}(20 \mathrm{~g} / \mathrm{L})$ and administered for 5 days. The enteral formula was an isoosmotic blended diet $(1 \mathrm{kcal} / \mathrm{mL})$. All patients were fed using a continuous drip-feeding protocol. In this protocol, the feeds were started at the rate of $25 \mathrm{~mL} /$ hour and then increased every 4-5 hours, provided the gastric residual volume was less than $200 \mathrm{~mL}$, until the target feeding rate was achieved (25-30 kcal/kg/day). The osmolarity and the $\mathrm{pH}$ of the feeding formula were the same before and after adding the artichoke powder. The pHs between the plain and after mixing formula were the same in range. The study protocol gave the processed artichoke for only 5 days. In this study, all patients were fed using the continuous drip-feeding protocol. In this protocol, the feeds were started at the rate of $25 \mathrm{~mL} /$ hour and then increased every 4-5 hours - provided the gastric residual volume was less than $200 \mathrm{~mL}$, until feeding target was achieved. There were no changes in medications after beginning the artichoke-enriched formula. Blood tests including complete blood count, blood urea nitrogen, serum creatinine, electrolyte, liver function tests, and glucose were obtained within 24 hours before receiving the artichoke-enriched formula, and after receiving it for 5 days. We recorded complications including vomiting and tube clogging or obstruction. The gastric residual volume was regularly measured every 4 hours (30 times in 5 days). We also recorded the severity of disease and comorbidity at the time of initiation and the daily sum of diarrhea score.

\section{Statistical Analysis}

The before and after laboratory values were compared using the paired $t$ test and the Wilcoxon sign-rank test for parametric and nonparametric distribution, respectively. The continuous variables were reported as mean (standard deviation, SD) or median (interquartile range, IQR) for normal and nonnormal distribution, respectively. The significant statistical difference was $p$ value $<0.05$.

\section{Results}

\section{Physical Property and Dietary Fiber Profile after Processing}

The product yield of processed Jerusalem artichoke was $10.3-12.6 \%$. The moisture content was 3.1-3.3\% and water activity $\left(a_{\mathrm{w}}\right)$ was 0.39 0.40 . The color values by $L^{*}, a^{*}$, and $b^{*}$ were $65.8-66.1,7.6-7.7$, and 20.8-21.6, respectively. Regarding the viscosity analysis (Fig. 1 and Table 1), the pasting curve or viscosity curve (Fig. 1) demonstrated that the peak viscosity of 5 and $10 \%$ artichoke powder were $0.2-0.3$ minutes, the peak viscosities were 210 and 275 RVU, respectively (Table 1). The viscosity curves were significantly decreased after 0.5 minute and viscosities less than $50 \mathrm{RVU}$ were independent of 

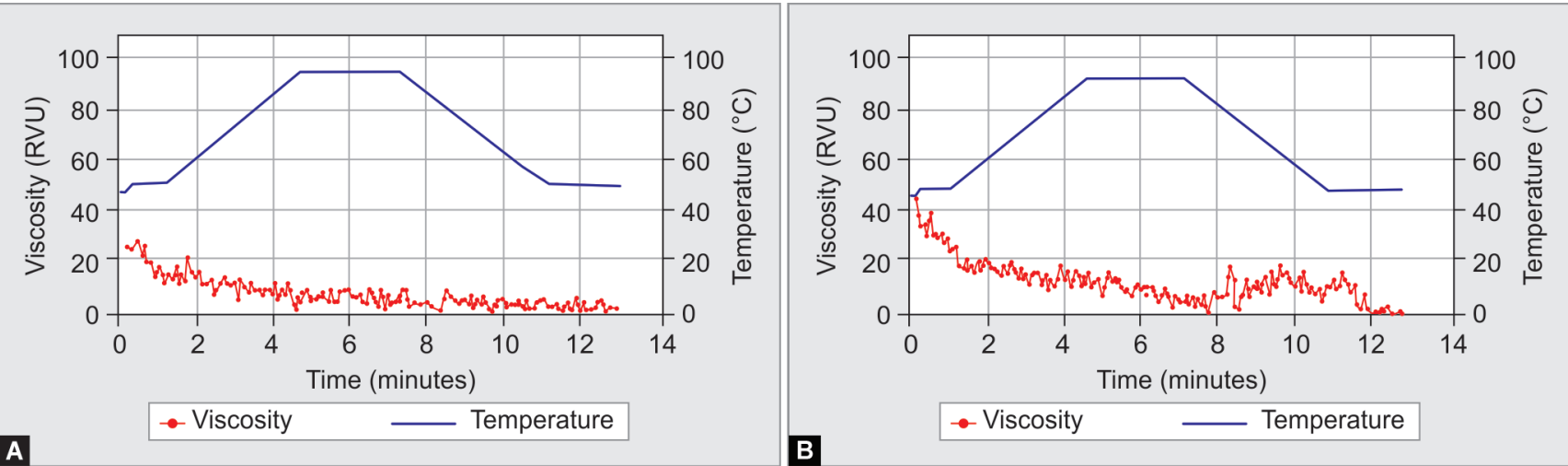

Figs 1 A and B: Pasting curve: (A) $5 \%$ of artichoke by weight; (B) $10 \%$ of artichoke by weight

Table 1: Jerusalem artichoke properties after processing

\begin{tabular}{|c|c|}
\hline Property & Value \\
\hline $\begin{array}{l}\text { Processing weight per } 100 \mathrm{~g} \text { of raw weight (\% } \\
\text { yield) }\end{array}$ & $10.3-12.6$ \\
\hline \multicolumn{2}{|l|}{ Physical properties of processed artichoke } \\
\hline Moisture content (\%) & $3.1-3.3$ \\
\hline Water activity $\left(a_{\mathrm{w}}\right)^{\dagger}$ & $0.39-0.40$ \\
\hline Color L* (lightness) ${ }^{\ddagger}$ & $65.8-66.1$ \\
\hline Color $\mathrm{a}^{*}\left(\right.$ redness) ${ }^{\ddagger}$ & $7.6-7.7$ \\
\hline Color b* (yellowness) ${ }^{\ddagger}$ & $21.7-20.8$ \\
\hline \multicolumn{2}{|c|}{$\begin{array}{l}\left.\text { Peak (at } 95^{\circ} \mathrm{C}\right) / \text { lowest }\left(\text { at } 95^{\circ} \mathrm{C}\right) / \text { final viscosity } \\
\text { of pasting curve }(\mathrm{RVU})\end{array}$} \\
\hline $5 \%$ artichoke powder & $8 / 0.5 / 0.3$ \\
\hline $10 \%$ artichoke powder & $14 / 3.0 / 0.6$ \\
\hline $\begin{array}{l}\text { Viscosity change after mixing } 2 \mathrm{~g} \text { in } 100 \mathrm{~mL} \\
\text { enteral feeding formula at } 21-22^{\circ} \mathrm{C}(\mathrm{RVU})\end{array}$ & $0.6-0.7$ \\
\hline \multicolumn{2}{|l|}{$\begin{array}{l}\text { Fiber contents of processed Jerusalem arti- } \\
\text { choke powder }(\mathrm{g} / 100 \mathrm{~g})\end{array}$} \\
\hline Total dietary fiber & $20.8-21.6$ \\
\hline Insoluble fiber & $5.0-5.2$ \\
\hline Soluble fiber & $15.8-16.4$ \\
\hline Fructans (inulin + oligofructose) & $66.0-71.5$ \\
\hline $\begin{array}{l}\text { Total soluble fiber (fructans }+ \text { dietary soluble } \\
\text { fiber) }\end{array}$ & $81.8-87.9$ \\
\hline
\end{tabular}

${ }^{\dagger} a_{\mathrm{w}}$ equilibrium relative humidity (ERH)/ 100

${ }^{\ddagger}$ Color measurement: $L^{*}$, lightness; $a^{*}$, redness; $b^{*}$, yellowness (standard values of $L^{*}, a^{*}, b^{*}=46.24,2.80,18.24$ )

temperature (Fig. 1). These results indicated that the swelling of artichoke particles in the powder was very low. These hypotheses were confirmed by observing that the viscosity of the artichokeenriched enteral feeding formula increased by only 0.6-0.7 RVU. The dietary fiber content of the artichoke-enriched formula was $20.8-21.6 \mathrm{~g} / 100 \mathrm{~g} \mathrm{(5.0-5.2} \mathrm{of} \mathrm{insoluble} \mathrm{fiber} \mathrm{and} \mathrm{15.8-16.4} \mathrm{soluble}$ fiber), and the fructan content (inulin and oligofructose) was $66.0-71.5 \mathrm{~g} / 100 \mathrm{~g}$.

\section{Patient Outcomes of Pilot study}

Eleven patients were enrolled into the pilot study between June 2016 and June 2017. Six patients (54.5\%) were male. The mean age (standard deviation, SD) was 67.2 (11.7) years, the mean APACHE II score at admission (SD) was 16.8 (3.7), and the mean body mass index (SD) was 20.7 (2.5). Eight patients (72.7\%) were postoperative
(Table 2). Sepsis was the reason for ICU admission in $72.7 \%$. The comorbidities were diabetic mellitus $(6 / 11,54.5 \%)$, hypertension $(3 / 11,27.2 \%)$, malnutrition $(3 / 11,27.2 \%)$, and acute kidney injury (3/11, 27.2\%).

At enrollment and before administration of the artichokeenriched formula, the median (IQR) of the diarrhea score was 18 (12-26) (Fig. 2). The median diarrhea score decreased after the artichoke-enriched formula was started. This effect of improvement started on day 2 [median different diarrhea score (IQR): -4 ( -8 to $0) ; p=0.03]$ and peaked by days 4 and 5 [ $-7(-10$ to -3$) ; p<0.01$ and $-8(-12$ to -4$) ; p<0.01$, respectively]. At the end of study on day 5 , the proportion of patients whose diarrhea score was less than 12 was $63.6 \%(7 / 11)$. There were no reports of vomiting or tube clogging during the study period. Only three patients had gastric residual volume more than $200 \mathrm{~mL}$ (7 times/total 220 residual measurements; Table 3). Although the intensive care mortality was high at $36.3 \%(4 / 11)$, the causes of death were associated with disease process (sepsis with multi-organ dysfunction in two patients, respiratory failure in one patients, and late surgical complication in one patient) and were not associated with the study intervention. The laboratory results of complete blood count, blood chemistry, and liver function were not statistically different except serum sodium and chloride, which were slightly lower than before receiving artichoke-enriched formula at day 5 (Table 4).

\section{Discussion}

This study demonstrates the method of processing Jerusalem artichoke into powder, its properties, and the amount of fiber contained in the artichoke-enriched formula. Regarding the physical properties, the peak viscosity is the highest viscosity measured at temperature of $95^{\circ} \mathrm{C}$. This value is associated with the powder swelling and granule disruption rate. ${ }^{6}$ The hold viscosity is the lowest viscosity achieved during heating at $95^{\circ} \mathrm{C}$. This value means the viscosity changes from the disruption of the powder. ${ }^{6}$ The final viscosity is the mixing viscosity after temperature lowers to $50^{\circ} \mathrm{C}$. This number indicates the restructuring and retrograding of starch molecules. It refers to the ability of the powder to form the gelatinous paste after cooling. ${ }^{6}$ The high, medium, and low viscosities are classified as $>300,200-300$, and $<200 \mathrm{RVU}$, respectively. ${ }^{6}$ Our results demonstrate that gelatinous forming was low. The peak, holding, and final viscosities were low $(<200$ $\mathrm{RVU}$ ). These properties led to the very low alteration of viscosity after mixing of $2 \mathrm{~g}$ powder in $100 \mathrm{~mL}$ of the enteral feeding formula, as well as no report of tube clogging during feeding of the patients. 
Preparation and Clinical Study of Artichoke in EN

Table 2: Patient characteristics

\begin{tabular}{cllllllll}
\hline Case & Age & Gender & APACHE II & BMI & Diagnosis & Procedure & ICU admission \\
reason & Comorbidity \\
\hline 1 & 66 & Male & 22 & 24.1 & Fournier gangrene & Debridement & Sepsis & DM, HT \\
3 & 56 & Female & 12 & 22.9 & Lung cancer & VAT lobectomy & Postoperation & DM \\
4 & 74 & Female & 21 & 21.1 & Acute cholecystitis & Open cholecystectomy & Sepsis & DM, HT, AKI \\
5 & 69 & Female & 14 & 22.9 & Pneumonia & - & Sepsis & DM \\
6 & 57 & Female & 16 & 20.7 & Acute colitis & - & Sepsis & HT \\
7 & 48 & Male & 18 & 18.0 & Lung cancer with pneumonia & VAT pleurodesis & Sepsis & Malnutrition \\
8 & 77 & Male & 15 & 17.1 & Pneumonia & - & Sepsis & Malnutrition \\
9 & 82 & Female & 14 & 17.3 & Acute cholecystitis & Open cholecystectomy & Sepsis & HT \\
10 & 55 & Male & 21 & 22.8 & Necrotizing fasciitis & Debridement & Sepsis & DM, cirrhosis, AKI \\
11 & 73 & Male & 20 & 19.0 & Abdominal aortic aneurysm & Open repair AAA & Postoperation DM, HT, AKI \\
\hline
\end{tabular}

AAA, abdominal aortic aneurysm; APACHE II, acute physiologic and chronic health evaluation II score; AKI, acute kidney injury; BMI, body mass index; DM, diabetic mellitus; $\mathrm{HT}$, hypertension; VAT, video-assisted thoracoscope

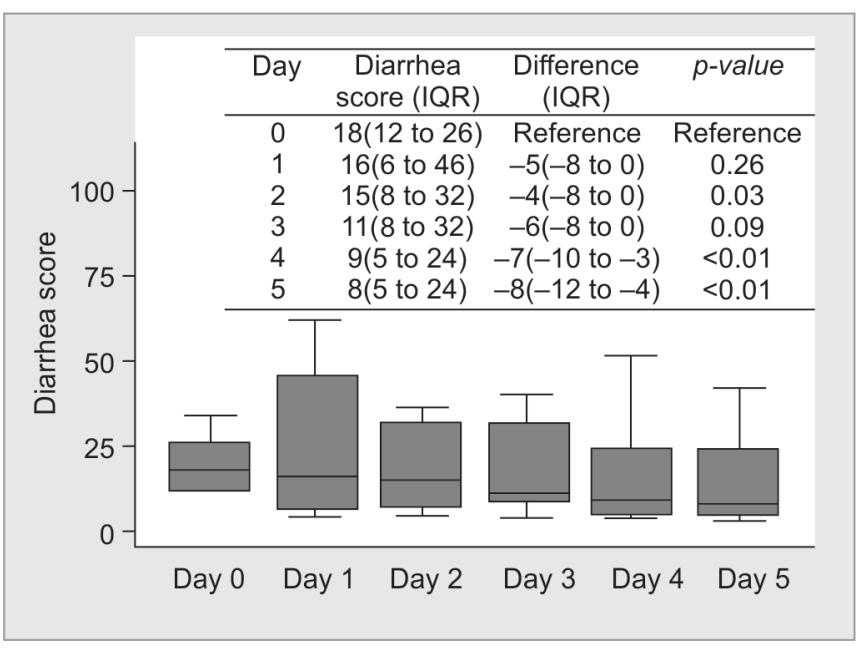

Fig. 2: Diarrhea score before (day 0 ) and after (days 1-5) artichoke mixed blenderized enteral feeding

The Jerusalem artichoke tuber contains highly soluble fiber. In a fresh sample, the sum of dietary fiber is around $25 \mathrm{~g} / 100 \mathrm{~g}$ fresh weight (FOS $5.16 \mathrm{~g}$ and inulin $19.4 \mathrm{~g}$ ). ${ }^{7}$ After processing, the total soluble fiber increased to $81.8-87.9 \mathrm{~g} / 100 \mathrm{~g}$ of dried powder. This figure is comparable to the hydrolyzed guar gum. Yoon et al. reported that the partially hydrolyzed guar gum has $75 \mathrm{~g} \%$ of soluble fiber. ${ }^{8}$ There is no consensus recommendation on the appropriate amount of fiber in enteral formulas. However, since the year 2000, enteral formula mixed with different sources of fiber has been reported in randomized control trials in critically ill patients (Table 5). However, the fiber doses varied from 2.6 to $22 \mathrm{~g} / \mathrm{L}^{3,9-14}$ and 9 to $22 \mathrm{~g} / \mathrm{L}$ in adults. ${ }^{3,9-12,14}$ These formulas comprised of different soluble fiber in the ranges of $2.6-16.5 \mathrm{~g} / \mathrm{L}^{3,9-14}$ and 3.75-16.5 g/ $\mathrm{dL}^{3,9-12,14}$ in adults. In our study, the amount of fiber with artichoke powder was provided in the range of previous reports of 16.4-17.6 $\mathrm{g}$ of soluble fiber/L.

In our pilot study in 11 patients in surgical ICU, diarrhea improved in $63.6 \%$. The diarrhea score improved after the 2 nd day (Table 3 and Fig. 2). There were no complications during feeding except high gastric residual volume (GRV), which led to the interruption of enteral feeding. We also used the cut-off point as
$200 \mathrm{~mL}$ in our institute guidelines due to the small body phenotype of Thai people and Thai recommendations to use $200-250 \mathrm{~mL}$ in patients who are receiving enteral feeds. ${ }^{15,16}$ The reduction of diarrhea after giving the soluble fiber might be explained from microbiota alterations. O'Keefe et al. reported the quantitative polymerase chain reaction (qPCR) of microbial 16S rRNA genes and Human Intestinal Tract Chip (HITChip) microarray analysis after giving soluble fiber to critically ill patients. Fiber supplements were found to create a significant increase in fecal short-chain fatty acid and microbial counts of specific butyrate producers. These resulted in the resolution of diarrhea in three of four of his enrolled patients. ${ }^{17}$ However, the results of using fiber-containing enteral formula in critically ill patients are still inconsistent. ${ }^{18,19}$ The American Society of Parenteral and Enteral Nutrition (ASPEN) guidelines mention that "we suggest that a commercial mixed fiber formula not be used routinely in the adult critically ill patient prophylactically to promote bowel regularity or prevent diarrhea"18 and "based on expert consensus, we suggest considering use of a commercial mixed fiber-containing formulation if there is evidence of persistent diarrhea." ${ }^{18}$ In a recent systematic review of dietary fibers in enteral nutrition of critically ill patient in eight studies, it was concluded that soluble fiber is safe in all hemodynamically stable intensive care unit patients. ${ }^{20}$ The fiber-containing formula may be beneficial for decreasing gastrointestinal symptoms especially diarrhea and may assist in treatment in this group of patients. ${ }^{20}$ However, further studies are required to answer the routine use of an enriched fiber diet in critically ill patients. ${ }^{20}$

There were no statistically significant differences in laboratory tests between before and after artichoke powder administration except serum sodium and chloride levels. But these differences were not clinically significant. In addition, these findings might be confounded by concomitant fluid therapy during the study period.

In addition to describing the production process, this study is a pioneer clinical study using the Jerusalem artichoke as a source of dietary fiber in surgical critically ill patients. However, there were some limitations in this study. First, because of no previous studies of similar products, we performed a pilot study to investigate the potential benefit in patients suffering from diarrhea. The small sample size and non-randomization without control arm led to insufficient power and random bias effects. However, the results of this study showed the mixing of artichoke powder into hospital 
Table 3: Clinical outcomes

\begin{tabular}{|c|c|c|c|c|c|c|c|c|}
\hline \multirow[b]{2}{*}{ Case } & \multicolumn{4}{|c|}{ Diarrhea score } & \multicolumn{3}{|c|}{ Enteral feeding complications } & \multirow[b]{2}{*}{ ICU discharge status } \\
\hline & Day 1 & Day 5 & Range $^{t}$ & Improvement ${ }^{\neq}$ & Vomiting & Tube clogging & GRV $>200 \mathrm{~mL}$ (times) & \\
\hline 1 & 12 & 8 & $(6-8)$ & Yes & No & No & No & Nonsurvived \\
\hline 2 & 12 & 5 & $(4-6)$ & Yes & No & No & Yes (1) & Nonsurvived \\
\hline 3 & 16 & 10 & $(10-15)$ & Yes & No & No & No & Survived \\
\hline 4 & 18 & 6 & $(8-13)$ & Yes & No & No & Yes (4) & Nonsurvived \\
\hline 5 & 34 & 24 & $(24-46)$ & No & No & No & No & Survived \\
\hline 6 & 15 & 3 & $(4-16)$ & Yes & No & No & No & Survived \\
\hline 7 & 26 & 24 & $(24-32)$ & No & No & No & Yes (2) & Survived \\
\hline 8 & 18 & 8 & $(8-16)$ & Yes & No & No & No & Survived \\
\hline 9 & 110 & 42 & $(32-52)$ & No & No & No & No & Survived \\
\hline 10 & 12 & 4 & $(4-6)$ & Yes & No & No & No & Survived \\
\hline 11 & 24 & 20 & $(20-32)$ & No & No & No & No & Nonsurvived \\
\hline
\end{tabular}

${ }^{\dagger}$ Range of diarrhea score between 2 nd and 5th day

FScore $<12$ at 5 th day; GRV, gastric residual volume

Table 4: Laboratory tests before and after receiving artichoke-enriched enteral feeds

\begin{tabular}{|c|c|c|c|c|c|}
\hline Laboratory & Before & $(S D)$ & After & $(S D)$ & $p$ value \\
\hline \multicolumn{6}{|l|}{ Complete blood count } \\
\hline Hemoglobin (g/dL) & 9.2 & $(0.9)$ & 9.3 & $(0.6)$ & 0.90 \\
\hline Hematocrit (\%) & 28.1 & $(2.7)$ & 28.4 & $(1.8)$ & 0.68 \\
\hline White blood cell count $\left(\times 10^{3} / \mathrm{mL}\right)$ & 10.7 & $(4.2)$ & 12.8 & $(4.3)$ & 0.10 \\
\hline Neutrophil (\%) & 80.4 & $(9.2)$ & 79.0 & $(8.9)$ & 0.38 \\
\hline Lymphocyte (\%) & 10.8 & $(6.4)$ & 11.4 & $(5.2)$ & 0.64 \\
\hline Platelet $\left(\times 10^{3} / \mathrm{mL}\right)$ & 195.4 & $(89.0)$ & 245.5 & $(100.6)$ & 0.06 \\
\hline \multicolumn{6}{|l|}{ Blood chemistry } \\
\hline Blood urea nitrogen (mg/dL) & 37.1 & $(18.0)$ & 36.3 & $(24.6)$ & 0.86 \\
\hline Creatinine $(\mathrm{g} / \mathrm{dL})$ & 2.2 & $(2.0)$ & 2.2 & $(2.2)$ & 0.33 \\
\hline Sodium (mEq/L) & 143.9 & $(14.8)$ & 138.9 & $(10.4)$ & 0.03 \\
\hline Potassium (mEq/L) & 3.9 & $(0.6)$ & 3.7 & $(0.5)$ & 0.12 \\
\hline Chloride (mEq/L) & 106.7 & $(8.5)$ & 102.4 & $(6.2)$ & 0.03 \\
\hline Bicarbonate $(\mathrm{mEq} / \mathrm{L})$ & 21.2 & $(2.8)$ & 21.7 & $(1.2)$ & 0.65 \\
\hline Glucose (mg/dL) & 139.7 & $(35.4)$ & 136.5 & $(32.0)$ & 0.72 \\
\hline \multicolumn{6}{|l|}{ Liver function test } \\
\hline Total bilirubin (mg/dL) & 0.8 & $(0.3)$ & 0.8 & $(0.3)$ & 0.81 \\
\hline Direct bilirubin (mg/dL) & 0.5 & $(0.3)$ & 0.5 & $(0.3)$ & 0.86 \\
\hline Albumin $(\mathrm{mg} / \mathrm{dL})$ & 2.5 & $(2.1)$ & 2.1 & $(0.8)$ & 0.23 \\
\hline Aspartate aminotransferase $(\mathrm{U} / \mathrm{L})$ & 31.6 & $(14.2)$ & 33.1 & $(13.0)$ & 0.39 \\
\hline Alanine aminotransferase (U/L) & 25.8 & $(34.0)$ & 26.5 & $(33.7)$ & 0.42 \\
\hline Alkaline phosphatase (U/L) & 194.3 & $(249.1)$ & 195.5 & $(248.4)$ & 0.28 \\
\hline Cholesterol (mg/dL) & 87.8 & $(35.3)$ & 90.2 & $(34.7)$ & 0.25 \\
\hline
\end{tabular}

Table 5: Amount of fiber in enteral formula in critically ill in previous and current study

\begin{tabular}{lllll}
\hline First author (year) & Type of fiber & Enrolled patients & Soluble $(\mathrm{g} / \mathrm{L}$ ) & Insoluble fiber $(\mathrm{g} / \mathrm{L})$ \\
\hline Caparros et al. (2001) & $9 \mathrm{~g} / \mathrm{L}$ of mixed fiber & Adults & 3.75 & 5.25 \\
Spapen et al. (2001) & $22 \mathrm{~g} / \mathrm{L}$ of guar gum & Adults & $16.5^{\dagger}$ & - \\
Rushdi et al. (2004) & $22 \mathrm{~g} / \mathrm{L}$ of guar gum & Adults & $16.5^{\dagger}$ & - \\
Spidler-Vesel et al. (2007) & $22 \mathrm{~g} / \mathrm{L}$ of guar gum & Adults & $16.5^{\dagger}$ & - \\
Chittawatanarat et al. (2010) & $15 \mathrm{~g} / \mathrm{L}$ of mixed fiber & Adults & 7.5 & 7.5 \\
Simakachorn et al. (2011) & $2.6 \mathrm{~g} / \mathrm{L}$ of inulin/FOS & Pediatrics & 2.6 & - \\
Yagmurdur et al. (2016) & $15 \mathrm{~g} / \mathrm{L}$ of mixed fiber & Adults & 7.0 & 8.0 \\
Current study & $20 \mathrm{~g} / \mathrm{L}$ of artichoke powder & Adults & $16.4-17.6$ & $1.0-1.1$ \\
\hline
\end{tabular}

${ }^{\dagger}$ Estimated by calculate soluble fiber in hydrolyzed guar gum is at least $75 \%{ }^{8}$

FStudy in pediatric critically ill patient; FOS, fructo-oligo saccharide 
formula was safe in terms of feeding processes (vomiting and tube clogging) with small occurrence of GRV $>200 \mathrm{~mL}$. Second, nearly two-thirds of patients had improved diarrhea symptoms but we had no data about intestinal physiological and biological alterations such as motility and gut microbiota. Future studies should investigate these issues.

\section{Conclusion}

The processed powder of Jerusalem artichoke tuber mixing in hospital enteral feeding formula slightly alters the viscosity of enteral feeds, and mixed Jerusalem artichoke formula may improve the diarrhea score in surgical critically ill patients. However, a future large randomized control trial should be performed to validate these results.

\section{ACKnowledgments}

We gratefully thank the following: surgical intensive care nurse on enrollment and data collection, the nutrition division on the preparation of fiber-mixed hospitalized diet, and Ms. Kanokkarn Juntaping the research assistant, coordinator between departments, data cleansing, and preliminary statistical analysis. We also would like to thanks Professor Peter Dodek (from Center for Health Evaluation and Outcome Sciences and Division of Critical Care Medicine at St. Paul's Hospital and University of British Columbia, Vancouver, Canada) for English editing of this final manuscript.

\section{References}

1. Tanjor S, Judprasong K, Chaito C, Jogloy S. Inulin and fructooligosacharides in different varieties of Jerusalem artichoke (Helianthus tuberosus L.). KKU Res J 2012;17(11):25-34.

2. Towviriyakul A, Jitinandana S, Judprasong K, Nitithamyong A. Formulation of Jerusalem artichoke (Helianthus Tuberosus L.) juice. Thailand: 1st Mae Fah Luang University International Conference; 2012.

3. Chittawatanarat K, Pokawinpudisnun P, Polbhakdee Y. Mixed fibers diet in surgical ICU septic patients. Asia Pac J Clin Nutr 2010;19(4):458464.

4. Joye $D$, Hoebregs $H$, Joye $D$, Hoebregs H. Determination of oligofructose, a soluble dietary fiber, by high-temperature capillary gas chromatography. J AOAC Int 2000;83(4):1020-1025. DOI: 10.1093/ jaoac/83.4.1020.

5. AOAC. Official Method of Analytical of AOAC International. 19th ed., Maryland, USA: AOAC international; 2016.

6. Shafie B, Cheng SC, Lee HH, Yiu PH. Characterization and classification of whole-grain rice based on rapid visco analyzer (RVA) pasting profile. Int Food Res J 2016;23(5):2138-2143.

7. Judprasong K, Tanjor S, Puwastien P, Sungpuag P. Investigation of thai plants for potential source of inulin-type fructans. J Food Comp Analysis 2010;24:642-649. DOI: 10.1016/j.jfca.2010.12.001.
8. Yoon SJ, Chu DC, Raj Juneja L. Chemical and physical properties, safety and application of partially hydrolized guar gum as dietary fiber. J Clin Biochem Nutr 2008;42(1):1-7. DOI: 10.3164/jcbn. 2008001.

9. Caparros T, Lopez J, Grau T. Early enteral nutrition in critically ill patients with a high-protein diet enriched with arginine, fiber, and antioxidants compared with a standard high-protein diet. The effect on nosocomial infections and outcome. JPEN J Parenter Enteral Nutr 2001;25(6):299-308. DOI: 10.1177/0148607101025006299; discussion-9.

10. Spapen H, Diltoer M, Van Malderen C, Opdenacker G, Suys E, Huyghens L. Soluble fiber reduces the incidence of diarrhea in septic patients receiving total enteral nutrition: a prospective, double-blind, randomized, and controlled trial. Clin Nutr 2001;20(4):301-305. DOI: 10.1054/clnu.2001.0399.

11. Rushdi TA, Pichard C, Khater YH. Control of diarrhea by fiber-enriched diet in ICU patients on enteral nutrition: a prospective randomized controlled trial. Clin Nutr 2004;23(6):1344-1352. DOI: 10.1016/j. clnu.2004.04.008.

12. Spindler-Vesel A, Bengmark S, Vovk I, Cerovic O, Kompan L. Synbiotics, prebiotics, glutamine, or peptide in early enteral nutrition: a randomized study in trauma patients. JPEN J Parenter Enteral Nutr 2007;31(2):119-126. DOI: 10.1177/0148607107031002119.

13. Simakachorn N, Bibiloni R, Yimyaem P, Tongpenyai $Y$, Varavithaya W, Grathwohl D, et al. Tolerance, safety, and effect on the faecal microbiota of an enteral formula supplemented with pre- and probiotics in critically ill children. J Pediatr Gastroenterol Nutr 2011;53(4):174-181. DOI: 10.1097/MPG.0b013e318216f1ec.

14. Yagmurdur $\mathrm{H}$, Leblebici F. Enteral nutrition preference in critical care: fibre-enriched or fibre-free? Asia Pac J Clin Nutr 2016;25(4):740-746.

15. Clinical Practice Recommendation for the nutrition management in adult hospitalized patients 2017. Accessed at http://www.spent.or.th/ uploads/event/20171219_5a38b6392af47_guidelines\%20EN\%20 final.pdf.

16. Chittawatanarat K, Sathornviriyapong S, Polbhakdee Y. Gradual sucrose gastric loading test: a method for the prediction of nonsuccess gastric enteral feeding in critically ill surgical patients. Indian J Crit Care Med 2015;19(2):92-98. DOI: 10.4103/09725229.151017.

17. O'Keefe SJ, Ou J, Delany JP, Curry S, Zoetendal E, Gaskins HR, et al. Effect of fiber supplementation on the microbiota in critically ill patients. World J Gastrointest Pathophysiol 2011;2(6):138-145. DOI: 10.4291/wjgp.v2.i6.138.

18. McClave SA, Taylor BE, Martindale RG, Warren MM, Johnson DR, Braunschweig C, et al. Guidelines for the Provision and Assessment of Nutrition Support Therapy in the adult critically ill patient: Society of Critical Care Medicine (SCCM) and American Society for Parenteral and Enteral Nutrition (A.S.P.E.N.). JPEN J Parenter Enteral Nutr 2016;40(2):159-211. DOI: 10.1177/0148607115621863.

19. Kamarul Zaman M, Chin KF, Rai V, Majid HA. Fiber and prebiotic supplementation in enteral nutrition: a systematic review and metaanalysis. World J Gastroenterol 2015;21(17):5372-5381. DOI: 10.3748/ wjg.v21.i17.5372.

20. Reis AMD, Fruchtenicht AV, Loss SH, Moreira LF. Use of dietary fibers in enteral nutrition of critically ill patients: a systematic review. Rev Bras Ter Intensiva 2018;30(3):358-365. DOI: 10.5935/0103-507X.20180050. 